\title{
Nigeria-Uganda Collaboration in Elimination of Worst Form of Child Labour: A Strategic Leadership Approach to Achieve SDGs.1 and 4
}

\section{Nwabuko OC*1,2,3, Nnaji TO ${ }^{4}$, Nwamoh UN and Emma-Ukaegbu UC ${ }^{5}$}

${ }^{1}$ Department of Haematology and Blood Transfusion, Federal Medical Centre, Nigeria

${ }^{2}$ Department of Haematology, College of Health Science, Abia State University, Nigeria

${ }^{3}$ Department of Public Health Sciences, USA

${ }^{4}$ Department of internal medicine, Alex Ekwueme Federal University Teaching Hospital, Nigeria

${ }^{5}$ Department of Community Medicine, Federal Medical Center, Nigeria

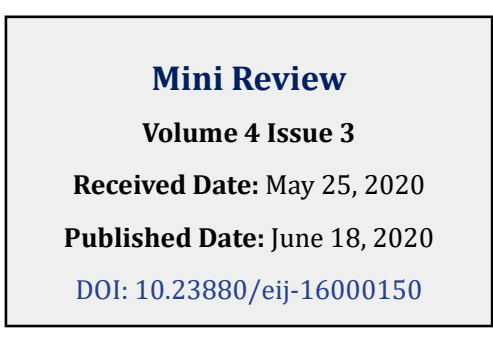

DOI: $10.23880 /$ eij-16000150

*Corresponding author: Ogbonna Collins Nwabuko, Department of Haematology, Federal Medical Centre, Aba Road, PMB 7001, Umuahia, Abia State, Nigeria, Tel +234 803704 6537; Email: ogbollins2002@yahoo.com

\section{Abstract}

Child labour is the current synonym for the age-long "slave trade" practiced in the African continent before the World War-II. This harmful practice is becoming a global challenge, especially in sub-Saharan Africa where a worst form of child labour is predominant due to poverty, and illiteracy. It is posing a threat to the survival of the teeming youths from this part of the world as it is responsible for several health challenges, brain drain, juvenile delinquencies and increased number of "out of school children" in the target population. This study is a systematic review of the global impact of the worst form of child labour and how the collaborations of member nations of low- and low-middle-income countries (LICs-LMICs) can mitigate this growing tide. The terms (keywords): worst form of child labour in Nigeria and Uganda were used as the medical subject headings for the search strategy to derive the PICO informed research questions. The PubMed, MedLine, African Journal Online, Google scholar and the research database were explored. This article is analyzed and grouped according to the following categories: introduction, comprehensive action plan, vision, mission statements of my organization, how to develop agenda partnership with Uganda to address SDG 1 and 4, philosophy of working in Uganda, pre- and post-visitation preparations, logistics/time frame/ cost/stakeholders and program evaluation.

In conclusion, the globalization of ideas and differences of member nations could be a one strategic leadership approach of solving the problem of worst form of child labour in sub-Saharan Africa. However, the intervention of agencies specialized in dealing with child trafficking and child labour is needed to fight this hydra-headed monster to a stand-still.

Keywords: Worst Form of Child Labour; Collaboration; Sdgs; Uganda; Nigeria

Abbreviations: LMIC: Low-Middle-Income Country; WBBI: Word Bank Bank Indicator; LIC; Low-Income Country; PPP: Power Parity Prices; NHS: National Health Service; CHCTAC: Community HIV Counseling Testing And Awareness Campaign.

\section{Introduction}

The adoption of the Sustainable Development Goals in 2015 brought into limelight an era of data revolution with targets and indicators for proper evaluation of the outcomes 


\section{Epidemiology International Journal}

of these developmental goals [1]. The topmost priority of the SDGs is to break the chains of inequality, inequity, injustice and to create healthy nations for science, actions and health all over the world [2]. In order to achieve these goals, high, middle- and low-income nations of the world must come together in collaborations and partnership to improve on each other in becoming healthy nation characterized by good health indices in terms of high average life expectancy and reduced infant mortality rate [3]. The SDGs have therefore made it possible for member nations to collaborate, monitor, evaluate, and prognosticate the global economy, ecosystem and equality indices (the triple is of global prosperity) of our world [4]. These SDGs are globally accepted because they are integrated, holistic, inclusive, transparent, universal, sustainable and leave no one behind.

Nigeria is the presumed largest and richest country in Africa with a population of approximately 200 million people and a GDP of about $\$ 376.28$ billion and per capita income of about $\$ 5680$ [5]. The country's economy valued as the richest on the continent is defined as a mixed emerging market which has attained the status of low-middle-income country (LMIC), according to Word Bank Bank Indicator (WBBI) [6]. The robust oil and gas market has made Nigeria the 12th largest oil producer and 8th largest oil exporter in the world. Based on this economic strength, Nigeria ranks first and 16th in the nominal GDP and GDP per capita respectively in Africa [5].

On the other hand, Uganda is one of the poorest nations in the world with a GDP and GDP per capita of $\$ 25.53$ billion and $\$ 1005$ respectively and population of about 45 million. Based on her economic indices, Uganda ranks seventeenth and 41st in nominal GDP and GDP per capita respectively in Africa, hence, assumed the status of a low-income country (LIC).

Despite the wide disparities in the economic indices between Nigeria and Uganda, both countries share several indicators of poor health indices. Notably among them are poor quality education and poverty. Nigeria has a "rising poverty economy" with about $44.2 \%$ (91.8 million) of her population leaving in extreme poverty. It is estimated that the poverty rate in Nigeria is increasing at the rate 6 persons in every minute. "Extreme poverty" in this context is defined as living in less than $\$ 1.90$ a day, based on the 2011 Purchasing Power Parity Prices (PPP) while "rising poverty connotes an increasing absolute number of people in poverty, often associated with rapid population growth. Nigeria has a fertility rate of about $5 \%$ with a GDP rate of about $2.3 \%$. It is estimated to have the highest absolute number of out-ofschool children in the world. Nigeria ranked 153 out of 187 member nations based on 2013 UNDA Human Development Report (UNDP 2013)[7]. According to UNESCO report of
2014 , if one were to randomly select a child from the global population of out-of-school children of primary school age, approximately one in every five is likely to be a Nigerian. Out of 57 million children who are not enrolled in the school, Nigeria shares about 10.5 million (followed by Pakistan and Sudan which have 5.8 million and 2.8 million respectively) [8].

Similar to Nigeria, Uganda has one in five out-of-school primary school children, but is currently experiencing increase in enrolment of school-age children. The current global ranking of Uganda is 136 th out of 176 countries. Unlike Nigeria which has a rising poverty economy, Uganda has an "off-track economy" which is better than Nigeria. By this it means that Uganda poverty level is reducing but at a slower speed than the counterfactual average speed recommended by SDG. The implication is that Uganda has lesser number of people living at extreme poverty level compared to Nigeria. Although Uganda still fall under the unhealthy nations of the world, it is relatively healthier than Nigeria based on the established health indices for assessing healthy nations by World Health Organization, but Nigeria is wealthier than Uganda based on World Bank Indicators [9].

Comparing Nigeria with Uganda, one may wonder how collaborations of the two countries (home and host countries respectively) could bring a change that could positively impact on achieving the SDG 1 and 4 . This could be possible by properly harnessing their respective strengths, weaknesses, opportunities and threats (SWOT analysis) on public health issues which they mutually share together.

In this episode, we are looking at strategic leadership approach to eliminate worst form of child labour in Uganda which is a hydra-headed monster impacting negatively in achieving multiple SDGs especially SDG 1 and 4 through Nigeria-Uganda collaboration. A comprehensive action plan to help assist Uganda reach an SDG, including vision, mission, values and objectives to develop a partnership with Uganda will be elucidated.

\section{Comprehensive Action Plan}

There are two major Sustainable Development Goals this action plan will address. They include:

SDG 1: End Poverty in all its forms everywhere.

SDG 2: Ensure inclusive and equitable quality education and promote lifelong learning opportunities for all.

The categories of child labour ranges from unpaid family workers, paid workers in agriculture sectors, apprenticeship, nomadic activities and household child caring. It is paramount to determine the condition under which the child works namely: is it a regular, time-demanding, intensive or 


\section{Epidemiology International Journal}

hazardous activity?

What are the demographic characteristics of the children who indulge in child labour: age, gender, socioeconomic status, educational status, health status, the circumstances of their families and the reason why they chose to work. Additional information on the physical and social environment where they are working would be vital while carrying out survey on child labour.

In crafting this action plan, the priorities will be on the targets and indicators of the SDGs 1 and 4. Poverty leads to Worst form of child labour while increase in number of outof-school children and poverty level are the products of this bad behavior. Therefore, the target of this action plan must be to empower the children population 5-17 years in Uganda and make education their principal occupation. The major targets and indicators that would achieve these goals are SDG 1.1, SDG 1.1.1; SDG 1.3, SDG1.3.1, SDG 4.1, SDG 4.1.1, SDG 4.3, SDG 4.3.1, SDG 4.4, SDG 4.4.1, SDG 4.5, SDG 4.5.1 [10].

There are some basic assessment and management questions that must be answered while conducting integrated response against WFCL. The questions include: what can we do to solve this? What can you do to solve this? Whom do we inform? How and when do we tell them?.

The process of crafting the action plan will require three fundamental steps namely: The process of developing the plan, priorities of the plan and the structure of the plan. The process of developing the action plan will take into cognizance involvement and engagement of the stakeholders. Stakeholder position in this context may include communitybased Participatory researchers, representatives of children (5-17 years) age group, local government authorities agents, councilors, members of the parliament, non-governmental organizations, civil society organization, environmental agents, national health service (NHS), donor agencies (National/International Agencies against child trafficking and child labour), etc. The essence of gathering the stakeholders is to make sure their needs and aspirations are met. The documentations of the plans will be followed by the ratification and discussion with the community leaders, men women and children themselves. After putting the findings into draft, another meeting with the technical team will be to review the draft from where it will be forwarded for final approval by the district council. This process may likely go on all the cities that make up Uganda.

The priorities of the action plan include: creation of public health awareness campaign of child labour using various modes of communications such as social media (Face book, blog, twitter, flicker, etc) , mass media (TV adverts, radio, etc), posters, bills in cultural friendly languages. Others include elimination of WFCL and national lists of hazardous works attributable to child labour; enforcement and intensification of legal actions against risk and consequences of child labour; establishment of interventions that will address the push and pull factors which cause children to embark on economic activities that will deprive them quality education and healthy life; and involvement of the families (parents or caregivers) of the children as target groups since they are strong contributors of child labour in the intervention [11].

\section{The Action Plan is divided into 6 sections viz:}

Section 1: Introduction of the plan, problem highlights, situational analysis of child labour and WFCL and their negative impacts.

Section 2: The process of developing the Action Plan including the priorities and structure of the plan.

Section 3: Policy Framework and the primary target group

Section 4: Goals, Objectives, principles of the plan

Section 5: Strategies Implementation and co-ordination framework

Section 6: Monitoring and Evaluation (M \& E)

\section{Goal of the Action Plan}

- To reduce the burden of WFCL in Uganda (Hoima) to the barest minimum and ensure that $90 \%$ of the affected children will live a decent life by 2030 .

- Strategic Objectives

- Increase enrolment and completion of primary level of education by $70 \%$ in 2025 (SDG 4.).

- Empower the children with social security and social assistance. (SDG 1.3.1)

- Create awareness and education on the consequences of WFCL (SDG 4.)

- Strengthening legal, policy and institutional frameworks to prevent entry into WFCL in Hoima district (SDG 16.).

- Withdrawal, rehabilitation, and integration of affected children with their families and communities (SDGs 11 \&16.).

Where partnership will take place $=$ Hoima, Uganda When partnership will work = January 2020 - December 2030

Who partnership will work $=$ Children $(5-17$ years $)$ population of Ugandan origin who engage in economic activities to the detriment of their academics and health: The primary target groups include children engaged in:

- Exploitative labour

- Commercial sex

- Trafficking

- Domestic work

- Involved in fishing

- Informal sectors (e.g., garage, markets, streets, food 


\section{Epidemiology International Journal}

preparation, luggage carriers)

The categories of children targeted include (Figure 1)

- Children with Disabilities;

- Orphans;

- Children in commercial agriculture - particularly in tobacco growing

- Children at risk of Child Labour:

- School dropouts;

- Child parents;

- HIV and AIDS affected and infected.
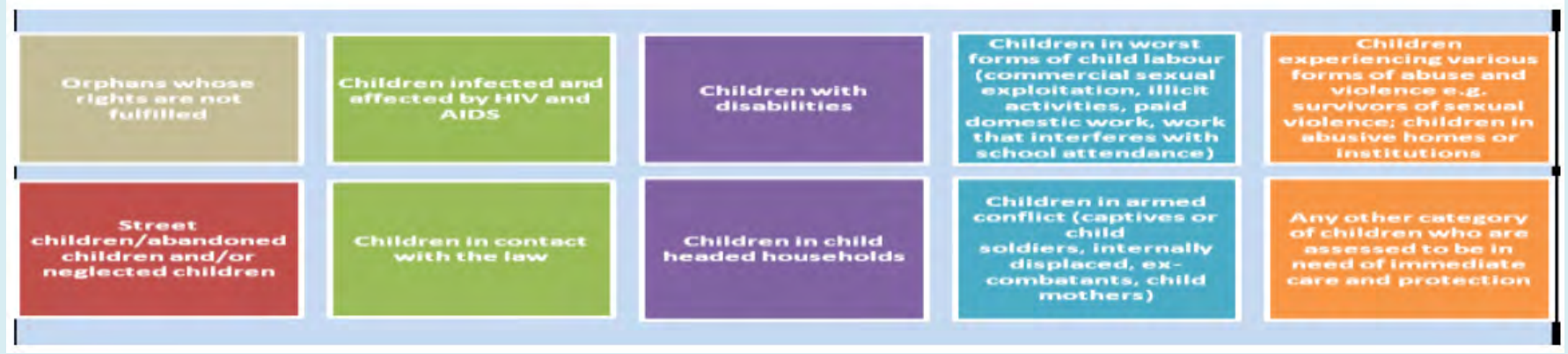

Figure 1: showing categories of vulnerable children in Uganda (Hoima).

\section{Vision Mission and Value of My Organization}

The intended organization to carry out this collaboration work with the Ugandan government is Firm Foundation healthy living centre. It is an organization founded with the vision to use an upstream approach to improve the average life-expectancy of Nigerian population. It is able to carry out this process using five thematic leadership approaches:

- Physical activities (Gymnastics)

- Screening tests against killer diseases (Cancers, Cardiovascular diseases, Obesity, Diabetes, Renal diseases, drug abuse, liver diseases, and nutritional anemias)

- Nutritional therapy

- Immunization/Vaccination

- Health Education

Firm foundation is committed to achieving SDG through ensuring quality health care (SDG 3), education (SDG 4) and improving the health indices of Nigerian population. It recognizes the fact that Child labour is a threat to the health of our children and has predisposed many of them to drug abuse, sexually transmitted diseases, early marriages (SDG 3) in addition to school drop-out (SDG 4) and poverty (SDG 1). Health literacy and education could be another strategy to actualize these SDGs.

Our Vision Statement: To reduce to the barest minimum the mortality rate in the society using strategic leadership approach to improve the quality and average life expectancy of the population.

Our Mission Statement: To create a healthy environment through public health education, physical activities, screening, research, therapeutic interventions and supportive care of the debilitated.

Our Motto: Reaching out to the unreached with preventive, promotive and protective health (Acronym: Reaching out to the unreached with the 3 Holy Ps of Sustainable Development).

\section{Our Core Values:}

- A Strategic Community and rural health care delivery

- Community HIV Counseling Testing and awareness campaign (CHCTAC)

- Supportive (Palliative) care

- Accountability to beneficiaries

- De-stigmatization

- Mission support

My organization will work in collaboration with other organization passionate for child labour to effectively carry out this partnership plan of eliminating child labour in Uganda children.

\section{How to Develop Partnership with Uganda to Address SDG 1 and 4}

Despite the Child labour act which prohibits children less than 12 years from engaging in child labour there are over 2 million Ugandan children involved in child labour. It is estimated than $70 \%$ of these children are engaged in agribusiness such as tobacco, coffee and gold mining. A non-governmental organization known as the Stop Child Labour Coalition Working group is at the frontline to curb the menace in Uganda. This coalition group which is made 


\section{Epidemiology International Journal}

of a local organization (Hivos) works in collaboration with other international organizations from Asia, Africa and Latin America to reduce child labour including the WFCL.

Firm foundation healthy living centre would like to partner with the workforce of Stop Child Labour Coalition Working group to synergize this common goal of reducing the number of children in Child labour by marketing and communicating the targets and indicators of the SDG 1 and 4 enumerated above and possibly recommending adoption of behavioral theory as a model of change. The targets and indicators to be explored include:

SDG 1.1: To eradicate extreme poverty for all the $28 \%$ of children 5-17 years in Uganda by 2030. (i.e., children living on less than $\$ 1.9$ a day)

SDG 1.1.1: By the year 2030, $0 \%$ of children $5-17 \%$ will live below the international poverty line by sex, age, employment status, vulnerability or geographical location.

SDG 1.3: To implement appropriate social security protection systems and measures to achieve substantial coverage of poor and the vulnerable between 5-17 years in Uganda.

SDG 1.3.1: Increase the population of children covered by social security protection including the employed and unemployed by the year 2030. Roll out social investment schemes, skill acquisition schemes, small and medium entrepreneurial schemes dedicated for 5-17 years age group. These are poverty alleviation schemes.

SDG 4.1: To ensure that all girls and boys (5-17 years) in Uganda complete free equitable and quality primary and secondary school education leading to relevant and effective learning outcomes by 2030. Education must be a topmost priority for this age group.

SDG 4.1.1: Proportion of children 5-17 years: a) in grades $2 / 3$; b) at the end of primary; and c) at the end of lower secondary achieving at least a minimum of proficiency level in reading and mathematics will increase significantly

SDG 4.3: To ensure equal access to all boys and girls 5-17 years to affordable quality, technical, vocational and tertiary education if they are of age by 2030 . The vocational include skill acquisition programs which can generate decent jobs or self-reliance.

SDG 4.3.1: To increase the participation rate of youths between 5-17 years to $80 \%$ in formal and non-formal education by 2030 .

SDG 4.4: To significantly increase the number of youths and young adults (5-17 years) who have skills including technical and vocational for employment, decent jobs and entrepreneurship by 2030 .

SDG 4.4.1: Increase proportion of youths (5-17 years) with ICT skills by at least $90 \%$ by 2030 .

\section{Philosophy of Working in Uganda}

Child labour is an ill wind that blows no one any good in any society. It is a major global family health issue that needs to be tackled. It is a modern form of slavery and a major set-back to achieving multiple SDGs (eg SDG 1, 2, 3, 4,5 , etc.). Elimination of child labour especially the WFCL is the rationale of working in the host country, Uganda. The common philosophy here is that if child labour is allowed to thrive in Uganda, other African country is also in danger. By virtue of this collaboration and the implementation of the action plan, harmful consequences of child labour as well as the comprehensive interventions will be well spelt out for the public consumption. The instrument derived from this collaboration will serve as useful guidelines for the key actors at the local government, legislature, non-governmental organization, CSOs, private sectors, parliaments, national/ local health services, voluntary organizations and other sectors which are social change agencies. The outcome of this collaboration (action plan) may act as complimentary legal documents for the vulnerable population who are oppressed and abused in the society.

\section{Pre-and Post-Visitation Preparation}

The pre- visitation awareness will involve communication and submission of proposal of intention to partner with the country on elimination of child labour act. Public health awareness creation is paramount at this stage. The mode of information dissemination must be such that must be culture friendly and which the target population uses regularly. There may be need to engage the Stop Child Labour coalition group on radio adverts on how to stop child labour in the society. The messages must be such that would emotionally appeal to the target audience. Child labour must be integrated in the plan, budget and structure of the action plan. There is need to engage the target audience (children 5-17 years) on discussion and decision-making at this stage. The media houses, civil society, faith-based organizations, traditional and cultural leaders must be engaged at this stage.

The post visitation preparation has to do with implementation and co-ordination of the action plans. It is a strategic approach to execute the objectives and goals of the action plan. To successfully execute the project, the key players must show commitment at this stage.

\section{Logistics/Time Frame/Cost/Stakeholders}

Logistics involve:

- Capital expenditure (i.e., vehicle, bicycle, office, etc)

- Recurrent expenditure (i.e., staff salary)

- Training

- Travels 


\section{Epidemiology International Journal}

- $\quad$ Supplies (i.e, stationeries, computer, etc)

- Communication (social media, mass media, etc)

- Screening/Medicals/rehabilitation of the affected children

- Maintenance

- Direct estimated cost

- Contingency ( $5 \%$ of direct cost)

- Overhead (1\% of direct cost)

Time Frame: January 2020- December 2030 is 10 years duration

Cost: Depends on the target population. An estimated population of 2,000 000 Ugandan children within the age range of 5-17 years are into Child labour out of which about 94,000 are from Hoima District. So the cost would be a fraction of what it will take to stop 2 million children (probably 94,000/2,000,000). The cost of the above logistics over 10 years would be 10 multiplied by cost of running the logistic for one fiscal year (10X FY1)

Stakeholders: Include all those mentioned under key actors. CSOs, CBOs, MPs, children representatives, Traditional and cultural leaders, local government agents, health care providers, councilors, legal/policy makers, etc.

\section{Program Evaluation}

This involves periodic assessment of the already set targets and indicators as mentioned in the objectives. A preliminary baseline data is usually established subsequent assessments. The essence of evaluation is to monitor response to intervention and to identify gaps or emerging issues. (Table 1 shows an evaluation table).

Strategic Objective 1: The enrolment of and completion of primary level education and access to appropriate skills training programmes for children

\begin{tabular}{|c|c|c|c|c|}
\hline Outputs & Indicators verifiable & Mode of verification & Frequency & Challenges/risks \\
\hline $\begin{array}{c}\text { Learning environment } \\
\text { in WFCL region } \\
\text { improved }\end{array}$ & $\begin{array}{c}\text { Increase newly constructed } \\
\text { infrastructure (SDG 4) }\end{array}$ & $\begin{array}{c}\text { Procurement minute } \\
\text { inspection }\end{array}$ & 6-monthly & Funding availability \\
\hline $\begin{array}{c}\text { Strategic Objective 2: To increase access of social protection and social assistance services to households affected } \\
\text { and those at risk of WFCL }\end{array}$ & $\begin{array}{c}\text { Willingness to provide } \\
\text { micro-credit by micro- } \\
\text { finance institutes }\end{array}$ \\
\hline
\end{tabular}

\section{Conclusion}

Globalization of ideas and practices could be strategic leadership approach of solving nations' problems. The Uganda-Nigerian collaboration strategy on WFCL is a typical case scenario. This is by institutionalization of action plan with enforceable policy framework on the target population, using donor agencies of national and international repute against child trafficking and child labour as critical stakeholders.

\section{References}

1. United Nations (2013) Communiqué, meeting of the high-level panel of eminent persons on the post-2015 development agenda in Bali, Indonesia, United Nations.

2. Sachs J (2015) The age of sustainable development. Columbia University Press, New York.

3. Cuaresma JS, Fengler W, Kharas H, Bekhtiar K, Michael B, et al. (2018) Will the Sustainable Development Goals be fulfilled? Assessing the present and future global poverty. Palgrave communications 4(29): 1-18.

4. Baruah P (2020) 3 pillars of sustainability- Economic, Environmental, and Social.

5. World Bank (2018) Population Reference Bureau 2018, Nigeria.

6. Barrera-Osorio F (2006) The Impact of Private Provision of Public Education: Empirical Evidence from Bogota's Concession Schools. World Bank Policy Research Working Paper 4121, Education Unit, Human Development Network, World Bank, Washington, DC.

7. Khalid Malik (2013) Human Development Report 2013. The Rise of the South: Human Progress in a Diverse World. UNDP, New York.

8. UNESCO (United Nations Educational, Scientific, and Cultural Organization) (2010) World Data on Education. $7^{\text {th }}(E d n)$, Bureau of International Education, Paris, pp: $1-22$. 


\section{Epidemiology International Journal}

9. Central Intelligence Agency Report (2018) Nigeria-The World Fact book.

10. (2016) Inter-agency expert groups on SDGs (IAEGSDGs).
11. Parker JC, Thorson E (2009) Health communication in the news media landscape. NY: Springer Publishing Company, New York.

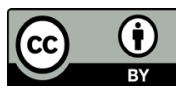

